\title{
Aspectos da construção temática de Arnold Schoenberg a partir de seus escritos teóricos sobre forma
}

\author{
Carlos de Lemos Almada (UNIRIO, Rio de Janeiro) \\ calmada@globo.com
}

\begin{abstract}
Resumo. Este artigo trata da construção temática do compositor Arnold Schoenberg, sob o ponto de vista de seus escritos teóricos sobre o assunto. Tal tipo de abordagem faz revelar, em plena atividade e em cores vivas, os traços que talvez mais caracterizem o pensamento composicional schoenberguiano, ou seja, as oposições tradição / inovação e teoria / prática. Na metodologia são utilizados exemplos extraídos de diversas fases criativas de Schoenberg (tonal, entre 1893 e 1908, e serial, 1923-51), num arco temporal do início e final de sua carreira, os quais são analisados a partir das definições que constam em obras didáticas sobre forma escritas pelo compositor, que se tornam assim o principal referencial teórico deste estudo. Pretende-se demonstrar que os tópicos teóricos elaborados por Schoenberg em seus escritos e derivados de minuciosas análises de obras dos grandes mestres (especialmente do período Clássico) servem de base consistente para sua própria prática composicional.

Palavras-chave: Arnold Schoenberg, construção temática, teoria, prática, formas clássicas.
\end{abstract}

\section{Issues of Arnold Schoenberg's thematic construction related to his theoretical writings about form}

Abstract. This paper deals with the thematic construction employed by composer Arnold Schoenberg, under the perspective of his own theoretical writings concerning this matter. This approach can vividly show some of the most characteristic issues of Schoenbergian compositional thinking, i.e., the oppositions of tradition / innovation and theory / practice. The methodology used in the present article consists of the analysis of examples extracted from several of the Schoenberg's creative phases (tonal, between 1893 and 1908-and serial, 1923-51), covering the extremes of his career. These pieces were analyzed under the perspective of the concepts stated in the didactic work about form written by the composer. These writings are, therefore, the main theoretical references of the present study, which aims at showing that the formal theory elaborated by Schoenberg in his texts, derived from detailed analysis of the works produced by the great masters (especially those of the Classic era) served as a solid basis for his own compositional practice.

Keywords: Arnold Schoenberg, thematic construction, theory, practice, classical forms.

\section{1 - Introdução}

Arnold Schoenberg (1874-1951) é um caso singular na história da música: além de figurar entre os maiores compositores de todas as épocas e ser considerado o principal e mais influente nome do modernismo musical, produziu uma vasta obra teórica, abrangendo diversos assuntos, dispersos em livros, coletâneas de ensaios e manuscritos (vários deles ainda inéditos), alguns deles entre os textos mais importantes já escritos sobre suas respectivas matérias. ${ }^{1}$ Talvez o mais marcante traço comum entre tais escritos teóricos seja a preocupação de Schoenberg de sempre apresentar didaticamente 0 objeto de estudo através de uma visão pessoal, calcada fortemente tanto em sua prática composicional quanto em minuciosas análises das obras dos grandes mestres do passado. Este artigo pretende examinar um dos aspectos no qual a dupla dicotomia tão caracteristicamente schoenberguiana - teoria $\mathrm{x}$ prática / tradição $\mathrm{x}$ inovação - torna-se bastante evidente: a construção temática.
0 estudo se estrutura em duas partes: inicialmente são abordados e definidos os conceitos "período", "sentença" e "pequena forma ternária" (a-b-a'), descritos teoricamente (e fartamente exemplificados com excertos da literatura musical) por Schoenberg em seu livro Fundamentals of Musical Composition (SCHOENBERG, 1990). A segunda parte consiste numa investigação analítica de como tais elementos formais são empregados na construção de temas em obras selecionadas do repertório do próprio Schoenberg.

Considerando o espaço exíguo que convém a um artigo, busquei reunir um conjunto mínimo de exemplos musicais que se ajustassem aos seguintes critérios: (a) restringir a escolha às peças instrumentais e não-programáticas; (b) cobrir o mais amplo período de tempo possível, procurando abranger todas as fases criativas do compositor; (c) escolher apenas entre temas que atuam em nítidas texturas de melodia acompanhada; (d) contemplar as três 
categorias focalizadas (período, sentença e pequena forma ternária), de modo a permitir comparações; e (e) buscar a maior diversidade possível em relação à instrumentação das obras escolhidas. A conciliação de tais requisitos resultou no quadro mostrado no Ex. 1:

\section{Observações:}

A única das fases composicionais não contemplada é a atonal (1908-1923). Isso se deve à baixa ocorrência, entre as obras schoenberguianas compostas nessa fase, de estruturas semelhantes (ainda que minimamente reconheciveis) às formas-escolares abordadas neste artigo. ${ }^{2} \mathrm{~A}$ elaboração do método de composição dodecafônico, de acordo com ROSEN (1983, p.105-108), permitiu a Schoenberg uma espécie de restauração de princípios tradicionais, num peculiar neoclassicismo, estabelecido principalmente através da organização formal (o que se reflete, em nível microscópico, também na construção dos temas);

Por outro lado, foram escolhidos temas representativos das três subfases dodecafônicas (inicial, intermediária e madura), já que estas possuem características distintas: 3 o que especificamente interessa, neste trabalho, é investigar se tais diferenças chegam a influir também na construção temática ;

Embora Schoenberg não tenha jamais abandonado a linguagem dodecafônica, retomou em seus últimos anos de vida o idioma tonal em algumas de suas composições. Nessas obras, no entanto, observa-se não uma simples volta ao passado, mas uma espécie de revisão, a partir da longa vivência experimentada distante da tonalidade. Torna-se assim, neste trabalho, especialmente interessante a comparação entre as estruturas dos temas tonais posicionados nos pólos opostos.

\section{2 - Definição dos termos 4}

Segundo SCHOENBERG (1990, p. 20), "uma idéia musical completa é articulada como período ou como sentença." São as duas estruturas preferencialmente escolhidas para a construção temática pelos compositores clássicos (principalmente os da tradição austro-germânica).

A forma-escolar (ou forma-padrão) do período, com oito compassos, apresenta uma subdivisão binária em antecedente (c. 1-4) e conseqüente (c. 5-8), normalmente separados por uma curta cesura. 0 antecedente consiste em um enunciado seguido de breve contraste (cada fragmento com dois compassos). 0 conseqüente inicia-se com uma repetição do enunciado (c.5-6), à qual se segue o desfecho cadencial (c. 7-8).

A forma-padrão da sentença também possui oito compassos e duas subdivisões principais, com quatro compassos cada: o primeiro membro (c. 1-4), formado por um enunciado (c. 1-2) seguido de sua repetição variada (c. 3-4), quase sempre numa estrutura de proposta / resposta ou, nos termos schoenberguianos, forma tônica / forma dominante (SCHOENBERG, 1990, p. 21-22). A segunda subdivisão forma o complemento (c. 5-8), no qual geralmente as idéias apresentadas no primeiro membro são brevemente elaboradas (c. 5-6), seguindo-se um desfecho cadencial (c. 7-8). Deve ser ainda acrescentado que Schoenberg considera a sentença como uma forma mais complexa e, em conseqüência, artisticamente mais evoluída que 0 periodo, pois ela "não apenas apresenta uma idéia, mas imediatamente inicia uma espécie de desenvolvimento" (ibid., p. 58). Período e sentença se diferenciam, portanto, na posição em que se dá a retomada do enunciado: imediatamente, no caso da sentença (seguindo-se sua elaboração) ou após a apresentação do contraste, no

Ex. 1 - Temas schoenberguianos selecionadas para análise

\begin{tabular}{|c|c|c|c|c|c|}
\hline $\begin{array}{l}\text { Identificação } \\
\text { do tema }\end{array}$ & $\begin{array}{l}\text { Número do } \\
\text { Movimento }\end{array}$ & Título da obra & $\begin{array}{c}\text { Ano de } \\
\text { composição }\end{array}$ & $\begin{array}{l}\text { Fase / subfase } \\
\text { composicional }\end{array}$ & Estrutura \\
\hline Tema principal & - & $\begin{array}{l}\text { Peça para piano em Dó\# menor } \\
\text { (sem } n^{\circ} \text { de opus) }\end{array}$ & 1894 & Tonal (inicial) & sentença \\
\hline Tema do trio & $\begin{array}{c}\text { II } \\
\text { (Scherzo) }\end{array}$ & Primeira Sinfonia de Câmara, Op.9 & 1906 & Tonal (final) & $\begin{array}{c}\text { a (periodo) - } \\
b-a^{\prime}\end{array}$ \\
\hline Tema principal & $\begin{array}{c}\mathrm{V} \\
\text { (Minueto) }\end{array}$ & Suíte para Piano, 0p.25 & 1923 & $\begin{array}{l}\text { Dodecafônica } \\
\quad \text { (inícial) }\end{array}$ & sentença \\
\hline Tema & - & Variações para Orquestra, 0p.31 & 1928 & $\begin{array}{l}\text { Dodecafônica } \\
\text { (intermediária) }\end{array}$ & $\begin{array}{c}a(\text { período })- \\
b-a^{\prime}\end{array}$ \\
\hline Tema principal & $\begin{array}{c}\text { II } \\
\text { (Andante) }\end{array}$ & Concerto para Violino, 0p.36 & 1936 & $\begin{array}{l}\text { Dodecafônica } \\
\text { (madura) }\end{array}$ & sentença \\
\hline Tema & - & $\begin{array}{l}\text { Variações para Banda Sinfônica, } \\
\text { Op. } 43\end{array}$ & 1943 & Tonal (retomada) & $\begin{array}{l}a \text { (sentença) } \\
-b-a^{\prime}\end{array}$ \\
\hline
\end{tabular}


período. Ambos podem servir de base para uma construção temática mais complexa: a pequena forma ternária (a-b-a'). De acordo com SCHOENBERG (ibid., p.119-136), uma pequena forma ternária esquemática possui extensão variável, dependendo da constituição de seus elementos: a subseção principal (a) pode ser um período ou uma sentença (portanto, com oito compassos), sendo seguida por uma subseção contrastante (b), em geral curta e composta por seqüências sobre um enunciado ambientado em uma região harmônica vizinha à principal. A recapitulação da subseção principal (a') tem a extensão normalmente reduzida.

Abreviaturas empregadas nos exemplos analisados Períodos: per. - período; ant. - antecedente; cons. conseqüente; en. - enunciado; contr. - contraste.

Sentenças: sent. - sentença; $1^{\circ} \mathrm{mbr}$ - primeiro membro; compl. - complemento; prop. - proposta; resp. - resposta;

Termos gerais: cad. - cadência; mod. - modelo (para seqüência); seq. - seqüência; rep. - repetição; ext. extensão; frag. - fragmento; des. - desenvolvimento; desf. - desfecho; var./... - variação do motivo ... (o mesmo para outras operações); dim. - diminuição; inv. - inversão; retr. - retrógrado; red. - redução; exp. - expansão; IP - idéia primordial [Grundgestalt]. ${ }^{5}$

\section{3 - Análises dos temas ${ }^{6}$}

\section{1 - Tema da Peça para Piano em Dó\# menor (1894)}

Como observa FRISCH (1993, p. 21-24), a peça em questão apresenta forte influência brahmsiana, tanto no aspecto harmônico como no de construção motívico-temática. Em relação ao tema principal, uma particularidade - também característica de Brahms, segundo o mesmo autor - salta aos olhos: a "manipulação métrica" de sua construção, com propósitos expressivos. 0 tema, apesar de escrito em compasso 2/4 (Ex. 2, versão original) soa como em 6/8, deslocado metricamente (o Ex. 3 transcreve o mesmo tema num formato que poderíamos considerar mais "natural" e propício para a presente análise). Estrutura-se como uma sentença quase convencional, pelo menos em relação ao primeiro membro. 0 complemento, no entanto, apresenta uma interessante e nova concepção, dividindo-se em dois fragmentos, num total de cinco compassos: um breve desenvolvimento motívico seguido pelo que poderia ser denominado, por analogia, "desenvolvimento métrico". Este resulta da omissão da anacruse esperada e das conseqüentes mudanças de fórmula compasso (percebidas apenas auditivamente), criando um efeito de intensificação rítmica, adequado para a conclusão que se segue. ${ }^{7}$

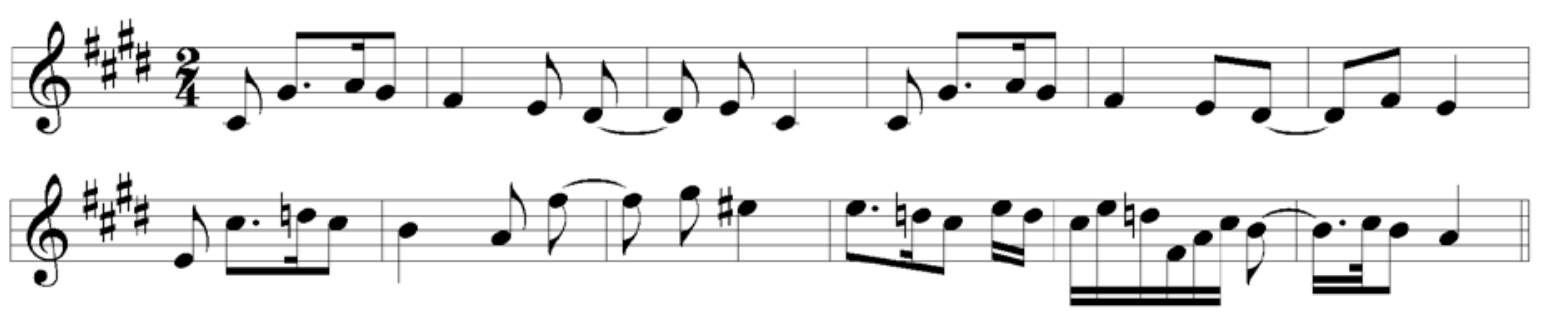

Ex. 2 - Peça para Piano em Dó\# menor (1894) - c. 1-11

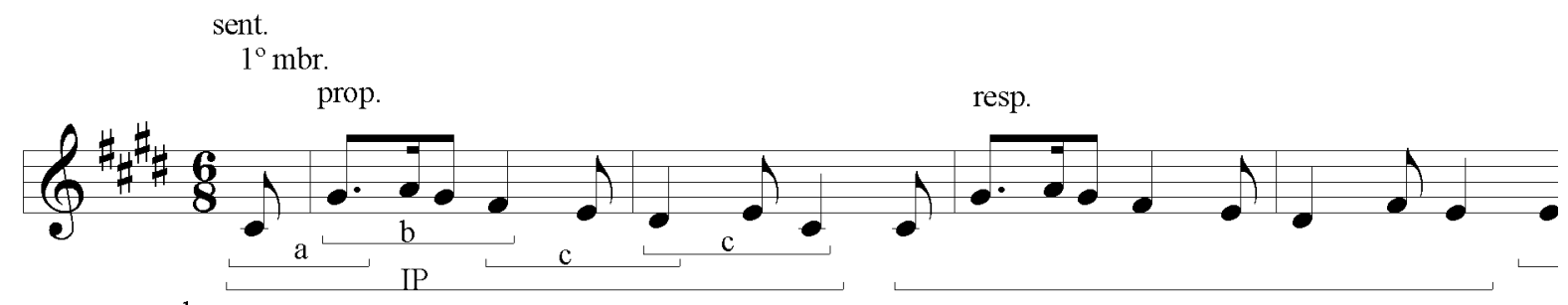

compl.

frag.1 (desenvolvimento motívico) frag.2 ("desenvolvimento métrico")

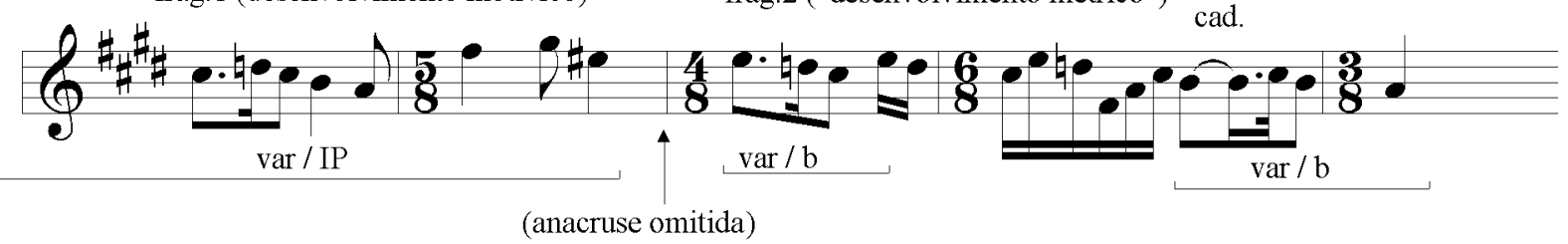

Ex. 3 - Transcrição métrica do Ex. 2 


\section{2 - Tema do Trio do Scherzo da Primeira Sinfonia de Câmara Op.9}

Incrustada como um "oásis" de clareza e transparência numa obra de textura polifônica extremamente densa e linguagem harmônica complexa, ainda que tonal, esta linha melódica (ver Ex. 4) cumpre perfeitamente o papel de contraste que convém a um tema do trio de um scherzo tradicional, de acordo com as observações teóricas do próprio compositor (SCHOENBERG, 1990, p. 141, 153). Estrutura-se como pequena forma ternária, com a subseção a em forma de um período tradicional ( $4+4$ compassos), a subseção $b$ consistindo em um modelo (baseado nos motivos principais) seguido de uma seqüência não estrita $(2+2$ compassos) e a subseção $a^{\prime}$ como uma retomada reduzida da subseção $a$, sendo quase uma cópia do antecedente (há aqui uma outra finalização harmônica).

\section{3 - Tema do Minueto da Suíte para Piano Op.25}

Fazendo parte de uma obra historicamente emblemática (a primeira a ser composta integralmente no método dodecafônico), este tema representa um interessante exemplo de construção tradicional desvinculada de quaisquer referências tonais. A princípio parece um contra-senso, já que períodos e sentenças surgiram como fruto das próprias manifestações das forças estruturais da tonalidade (por exemplo, a oposição tônica-dominante). ${ }^{8}$ No entanto, Schoenberg parece utilizar as formas-padrão - mais do que como um tributo ao passado - na tentativa de delas abstrair um "invólucro" básico para organizar as idéias melódicas oriundas da série. ${ }^{9} 0$ tema do Minueto estrutura-se, de maneira consideravelmente nítida, como uma sentença regular de oito compassos, como mostra o Ex. 5. 0 tema se apresenta como uma linha melódica composta: a segunda voz complementa a primeira, principalmente através das várias manifestações do motivo $a$. É ainda importante mencionar que as alturas que constituem 0 motivo $c$ (fragmento 2) representam em retrógrado, na notação alemã, as letras do nome de Bach (Sib-Lá-DóSi). No fragmento 4, seu correspondente na resposta, 0 mesmo motivo é bastante variado (transposto, invertido e intercalado por fusas), porém com seu contorno intervalar preservado, o que é suficiente para que o parentesco entre os fragmentos seja reconhecido auditivamente.

\section{4 - Tema das Variações para Orquestra}

Op. 31

0 tema desta obra (ver Ex. 6), a primeira no período dodecafônico a ser escrita por Schoenberg para grande orquestra (com todos os desafios e avanços que trouxe para o desenvolvimento do método serial) ${ }^{10}$ apresenta-se, como no tema do Trio do 0p. 9, em estrutura de pequena forma ternária (subseção $a$ em forma de período). Embora os dois temas compartilhem a mesma forma-padrão, a simples comparação entre ambos (Ex. 4 e Ex. 6) não deixa nenhuma dúvida sobre o maior grau de sofisticação da estrutura do tema do Op. 31 (desconsiderando as diferenças de linguagem harmônica, bem entendido). Essa constatação só confirma o quão flexíveis podem ser as fórmulas estruturais aqui examinadas: periodos, sentenças e, conseqüentemente, pequenas formas ternárias com eles construídas, em certa medida, são apenas abstrações, a partir das quais podem ser organizadas idéias musicais consideravelmente distintas. Neste tema, além de um intrincado trabalho de elaboração motívica que envolve o schoenberguiano princípio de variação em desenvolvimento, ${ }^{11}$ a estrutura-padrão de período sofre diversas mutações, tornando-se mais ampla e menos explícita: além de as convencionais

(a) per.

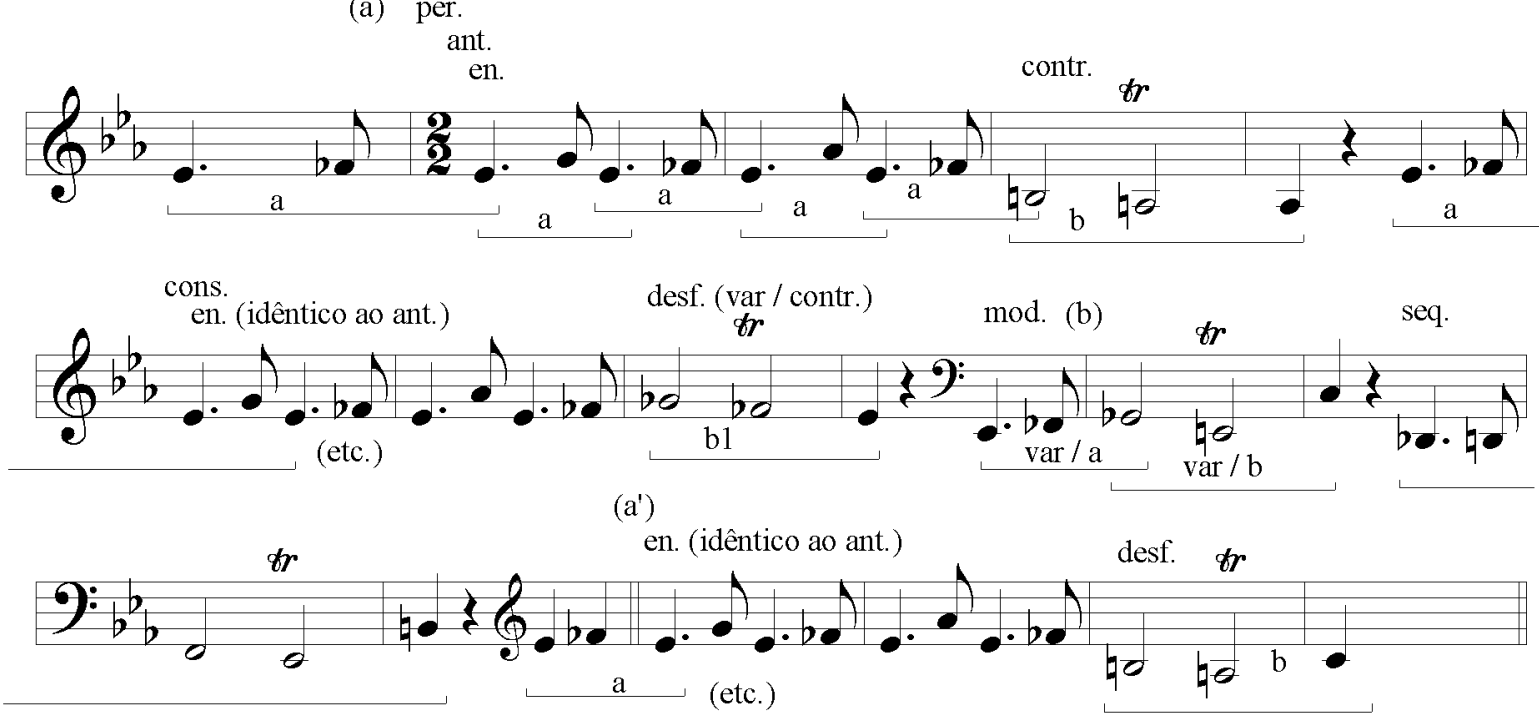

Ex. 4 - Primeira Sinfonia de Câmara Op. 9 / Trio (Scherzo) - c. 200-215 
$1^{\circ} \mathrm{mbr}$.
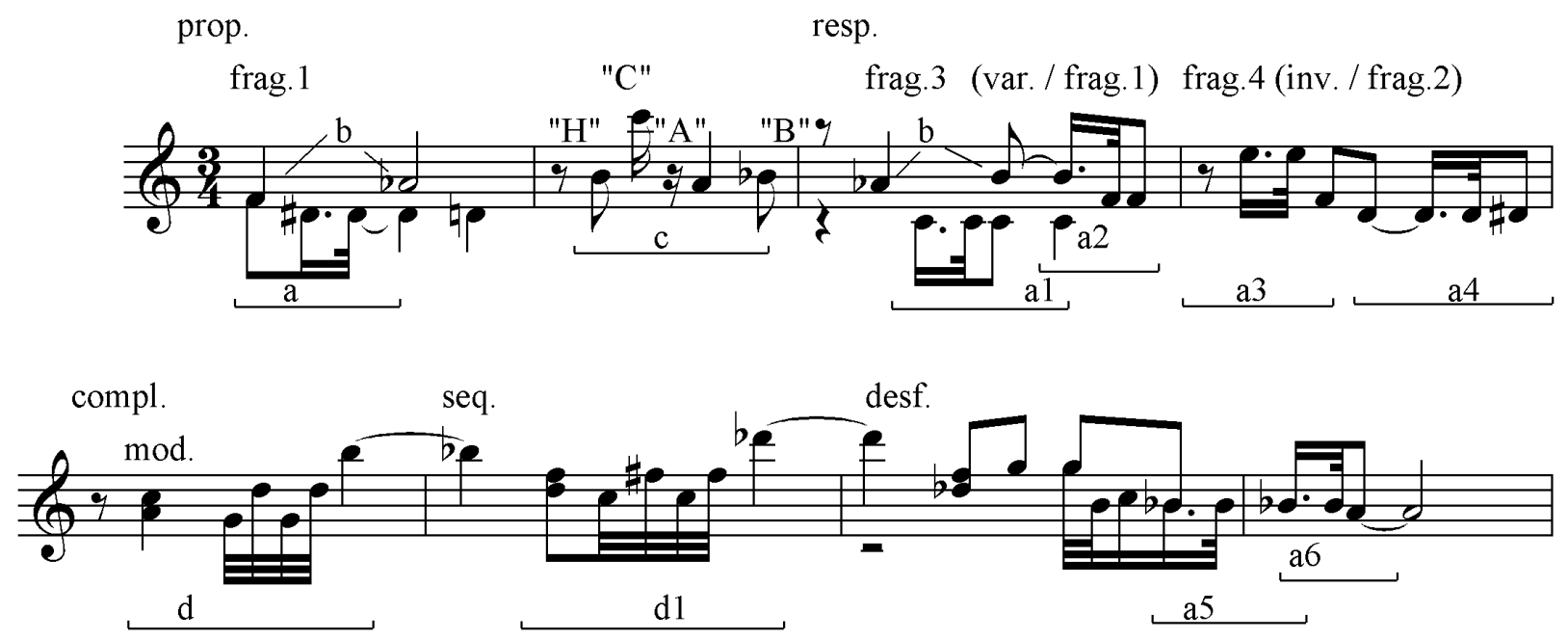

Ex. 5 - Suíte para Piano 0p. 25 / Minueto - c.1-8

(a) $(12 \mathrm{c}$.
per.

per. ant. $(7 \mathrm{c}$.)

frag. 1

en. frag. 2

* b - motivo intervalar $\left(5^{\circ}\right)$

** - omissão da resp.

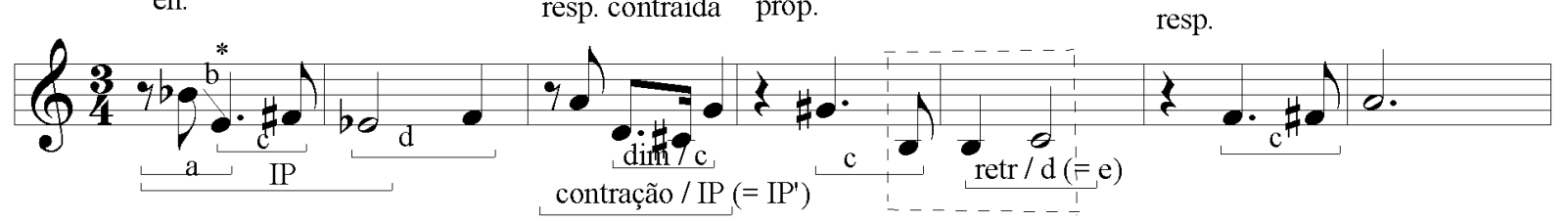

cons. $(5$ c.)

frag.1 frag. 2

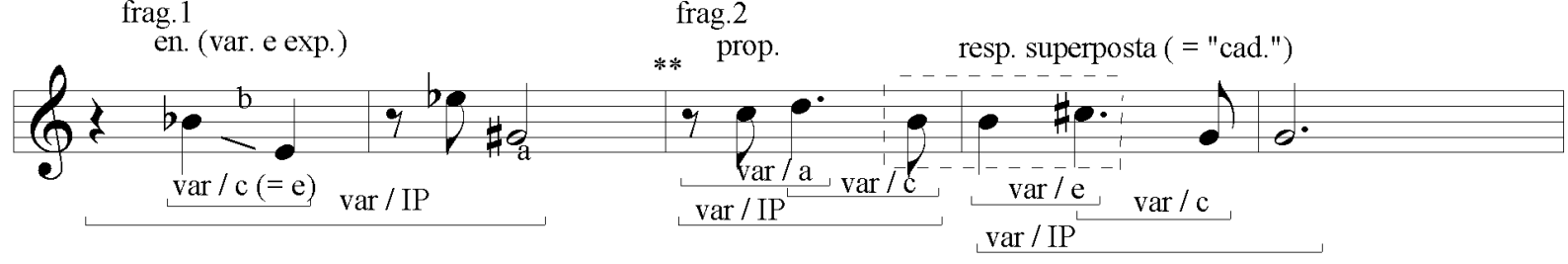

(b) mod. seq. var. (e estendida)

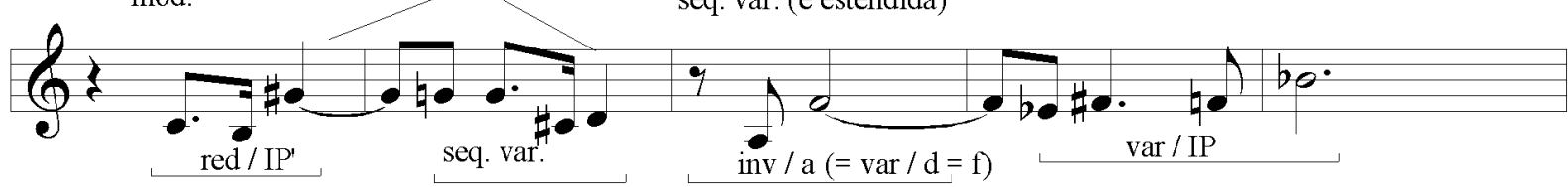

$\left(a^{\prime}\right)(=$ var $/$ ant. -7 c. $)$

frag. 1

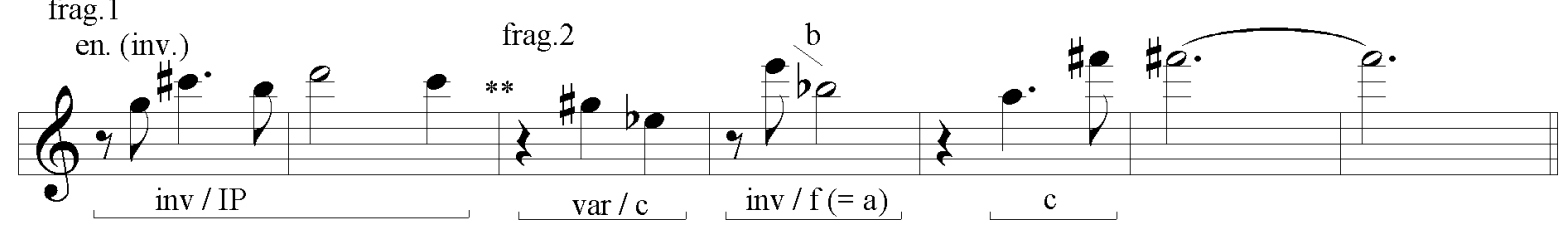

Ex.6 - Tema das Variações para Orquestra 0p. 31 - c. 34-57 
repetições ou seqüências mais ou menos literais serem substituidas por variações mais camufladas, a simetria formal original é quebrada por extensões, justaposições e supressões de segmentos esperados, que parecem decorrer naturalmente de uma necessidade de expressão mais aprofundada. É particularmente interessante analisar a segmentação da subseção $a$ : o primeiro fragmento, no antecedente, com três compassos, subdivide-se em dois segmentos: o enunciado e uma espécie de repetição variada e contraída deste. No fragmento correspondente dentro do conseqüente a resposta é suprimida, reduzindo-o a dois compassos. Um procedimento análogo é obtido na construção do segundo fragmento: como resultado, antecedente e conseqüente ficam com tamanhos distintos (7 e 5 compassos). A subseção $a^{\prime}$, como no tema do Trio do 0p. 9 (e de acordo com a descrição teórica schoenberguiana), é uma versão reduzida da subseção $a$ de 12 para 7 compassos; contudo, sua construção é mais próxima da estrutura do conseqüente do que do antecedente. A subseção contrastante $b$, como no Ex. 4, possui organização simples e simétrica, consistindo em um modelo seguido por seqüência variada e estendida $(2+3$ compassos).

\section{5 - Tema do Andante do Concerto para Violino Op. 36}

Citado por Schoenberg entre alguns exemplos de melodias expressivas de sua obra, construidas pela ação conjunta de "cérebro e coração" (SCHOENBERG, 1984, p. 73-75), este tema se apresenta de forma nitidamente simples e simétrica (principalmente se comparado aos exemplos anteriores). À parte do tratamento motívico, de notável economia, mostrado na análise do Ex. 7, podemos perceber uma estrutura de sentença, segmentada à maneira convencional $(4+4$ compassos). No entanto, uma extensão de um compasso é acrescentada ao final do complemento, ligando-o a uma codeta, cuja função (como habitualmente) é trazer equilibrio formal a todo o grupo. Apropriadamente, a codeta "liquida" 12 o material principal, resumido ao motivo $a$, que vai aos poucos perdendo sua característica rítmica, reduzindo-se a uma terça menor em duas colcheias (indicado por " $x$ ", no Ex.7), que passa então a ser repetida sucessivamente em oitavas diferentes.

\section{6 - Tema das Variações para Banda Sinfônica Op.43}

Este tema de caráter marcial, escrito em Sol menor, é um típico representante da fase de retorno de Schoenberg ao universo tonal. ${ }^{13}$ Adota a estrutura de pequena forma ternária, com as subseções principais ( $a$ e $a$ ) em forma de sentença (único caso entre os exemplos aqui examinados). Melódica e harmonicamente mais "palatável" do que os temas dodecafônicos, é, por outro lado, a estrutura formal mais complexa entre todas analisadas neste estudo, o que, por certo, resulta do grande amadurecimento construtivo do compositor. 0 que se torna ainda mais surpreendente é o fato de que essa complexidade parece ter brotado naturalmente, fruto das necessidades internas da construção, o que pode ser constatado na pura audição do tema. Sem comentar detalhadamente o trabalho de elaboração motívica (que talvez possa ser rivalizado apenas com o do 0p.31), a análise da estrutura do tema do 0p. 43 (ver Ex. 8) revela vários aspectos interessantes, apontando para uma ainda maior flexibilização das formas-padrão: embora a subseção $a$ se apresente quase como uma sentença convencionalmente simétrica (ainda que pesem os deslocamentos métricos no início do complemento e a extensão em seu final), a subseção $a^{\prime}$ - novamente, como em todos os casos, com extensão reduzida em relação à subseção $a$ - é apresentada numa engenhosa nova maneira. Como mostra o Ex. 9, Schoenberg

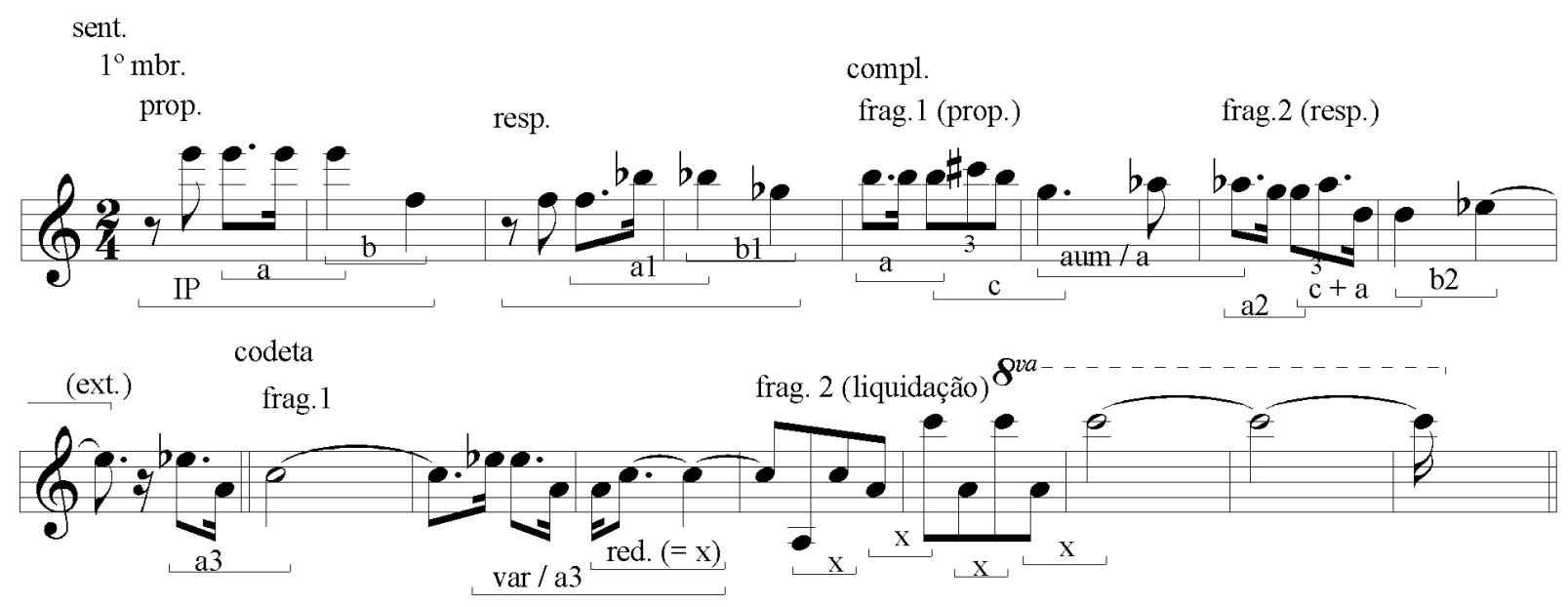

Ex. 7 - Concerto para Violino 0p.36 / Andante - c. 1-16 
cria para a reexposição uma versão compactada de sentença, combinando elementos característicos do primeiro membro e do complemento: a porção principal da proposta (que surge, inusitadamente, transposta a intervalo de segunda maior em relação ao original) é acoplada ao segmento $y$. Além disso, contraindo ainda mais a estrutura, a nova "forma-tônica" que surge dessa simbiose é superposta à "forma-dominante". A partir daí, volta-se à "normalidade", sem maiores modificações significativas, com uma variante do fragmento 2 do complemento, seguida de uma breve codeta, que leva à conclusão na tônica Sol.
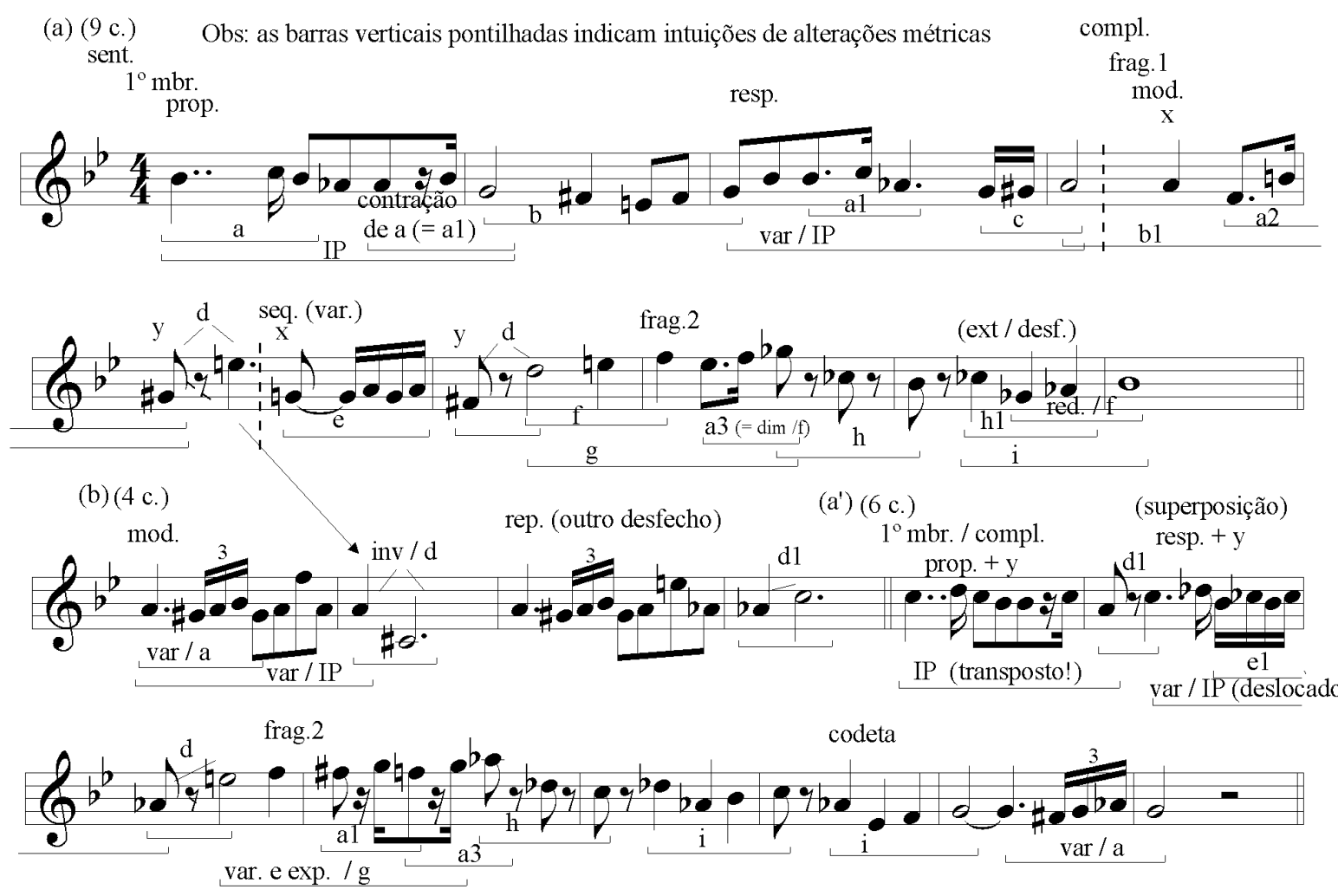

Ex. 8 - Tema das Variações para Banda Sinfônica 0p. 43 - c.1-21
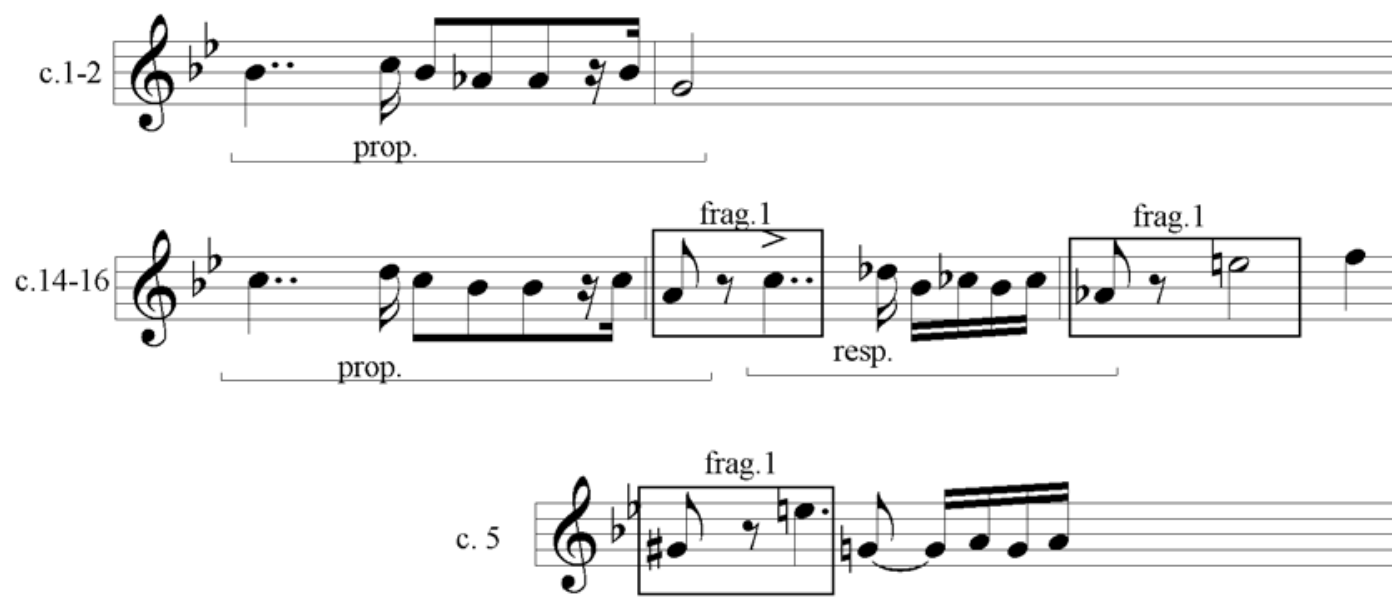

Ex.9 - Derivação do conseqüente 


\section{4 - Considerações finais}

Embora tenha plena consciência de que o exame comparativo de apenas seis casos não é suficiente para generalizações (o que é sempre temerário quando o assunto é arte), creio poder extrair dele algumas considerações interessantes:

Os escritos teóricos de Schoenberg sobre forma (e, mais especificamente, sobre a construção temática), focalizados na obra dos grandes mestres e voltada para suas estratégias didáticas, serviram também de base para sua própria prática composicional;

Isso se deu num arco bastante abrangente (de 49 anos, pelo menos), contemplando todas as fases nas quais a construção motívico-temática teve importância para 0 compositor (o que excluíria - pelo menos, até um estudo mais aprofundado comprová-lo - apenas o período atonal-expressionista);

$\mathrm{Na}$ transposição do campo teórico para o prático, e na adaptação de conceitos solidamente vinculados a uma estética de origem clássica e linguagem tonal para novas e particulares condições, Schoenberg empregou abstrações das formas-padrão "período", "sentença" e "pequena forma ternária", aprimorando-as com 0 passar do tempo. Tais abstrações possuem uma grande flexibilidade, não perdendo, entretanto, suas identidades em relação aos modelos originais. Mais do que fórmulas "modernizadas", mostram-se únicas a cada caso, com suas particularidades derivadas das condições que se apresentam - principalmente, da idéia primordial e do trabalho de elaboração motívica, realizando de maneira eficaz a organização temática; ${ }^{14}$

A comparação entre os temas tonais analisados (principalmente os do 0p. 9 e do 0p. 43, ambos pequenas formas ternárias) revela um forte amadurecimento construtivo: Schoenberg passa de uma estrutura mais esquemática, quadrática e "comportada" a uma outra muito mais assimétrica, flexivel e ousada, o que estaria diretamente associado aos processos de variação em desenvolvimento;

É também possivel comparar sumariamente as estruturas dos três temas dodecafônicos: a maior sofisticação formal do tema do 0 p. 31 em relação aos outros dois parece se ajustar às próprias caracteristicas da subfase a que pertence, de grande amadurecimento e desenvolvimento das possibilidades seriais. 0 maior "conservadorismo" formal dos temas do 0p. 25 e do 0p. 36 se explicaria por motivos parecidos: no tema do Minueto, pela recente volta de Schoenberg à elaboração temática convencional (o neoclassicismo descrito por Rosen - ver nota de rodapé $n^{\circ}$
8); no caso do tema Andante, pelas tendências "arcaizantes" do compositor, que se acentuam nas obras dodecafônicas mais tardias (LEIBOWITZ, 1997, p.290-293);

Alguns pontos em comum na construção das três pequenas formas ternárias focalizadas (0p. 9, 0p. 31 e 0p. 43): (1) a subseção $b$ possui curta duração (com 4 compassos, 5 no 0p. 31) e estrutura-se simetricamente como modelo e seqüência $(2+2 / 2+3)$; (2) a subseção $a^{\prime}$ é apresentada de forma abreviada, numa extensão menor do que a subseção

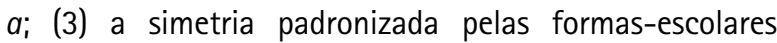
é "distorcida", o que acontece preferencialmente na subseção $a$, através de extensões, omissões e justaposições de estruturas (comparar principalmente as construções dos temas do 0p. 31 e do 0p. 43).

Tudo isso parece, por fim, vir confirmar aquele que é um dos principais traços da personalidade composicional de Schoenberg: a constante preocupação com o novo, que é, porém, sempre construído sobre uma sólida base tradicional, calcada em princípios clássicos-românticos, em especial, aqueles derivados da música austro-germânica. No caso específico do assunto aqui abordado, chama atenção o emprego de estruturas consideravelmente semelhantes às padronizações apresentadas no livro do compositor sobre análise formal (SCHOENBERG, 1990), deduzidas a partir de minuciosas análises de obras de compositores diversos, como Haydn, Mozart, Beethoven, Schubert, Schumann etc. Schoenberg dá, por assim dizer, nova vida a tais abstrações, adaptando-as às linguagens melódico-harmônicas adotadas em suas várias fases criativas. Tal procedimento parece ser, basicamente, fruto de uma necessidade de equilibrio: compensar, com um peso maior na identificação motívico-temática, a pouca (ou ausência total de) influência gravitacional de um centro de referência. As fórmulas de construção temática representam assim um dos mais importantes aspectos da ligação entre passado e futuro que tanto caracteriza 0 pensamento e a prática musical schoenberguiana.

A realização de novas pesquisas, alargando o grupo de obras analisadas (incluindo mesmo aquelas do período atonal do compositor), pode trazer importantes contribuições a este estudo, principalmente em busca de variantes construtivas (como aquela apresentada no tema do 0p. 43). Ampliando a mesma linha, o exame da dualidade teoria / prática na obra schoenberguiana pode ser estendido às formas cíclicas "clássicas", notoriamente empregadas pelo compositor: minueto, scherzo, sonata, rondó etc. E uma terceira opção, subjacente a estas, pode ser a abordagem da própria elaboração motívica, ligando-a a um estudo mais profundo sobre a variação em desenvolvimento na composição de Schoenberg. 


\section{Referências}

CRAWFORD, John e Dorothy L. Expressionism in Twentieth Century Music. Bloomington: Indiana University Press, 1993. FRISCH, Walter. Brahms and the principle of developing variation. Los Angeles: University of California Press, 1984. The early works of Arnold Schoenberg (1893-1908). Los Angeles: University of California Press,

1993.

LERDAHL, Fred. Tonal pitch space. Nova York: Oxford University Press. 2001.

LEIBOWITZ, René. Introduction à la musique de douze sons. Paris: L'Arche, 1997.

NELSON, Robert U. Schoenberg's variation seminar. The Musical Quaterly. Vol. L, No.2. April, 1964.

PERLE, George. Serial composition and atonality. Londres: Faber \& Faber, 1962.

ROSEN, Charles. Schoenberg. Barcelona: Antoni Bosch, 1983.

SCHOENBERG, Arnold. Style and idea: selected writings of Arnold Schoenberg. (Leonard Stein, ed.). Londres: Faber \& Faber, 1984. Fundamentals of musical composition. (Gerald Strang, ed.) Londres: Faber \& Faber, 1990.

The musical idea and the logic, technique, and art of its presentation. (Patricia Carpenter \&t Severine

Neff, trad. e ed.). Bloomington: Indiana University Press, 2006.

Notas

1 Ver, por exemplo, além dos livros que constam das referências bibliográficas deste artigo (SCHOENBERG, 1990, 1984 e 2006), os seguintes titulos: SCHOENBERG, Arnold. Harmonia. (Marden Maluf, trad.). São Paulo: Editora Unesp, 2001 (1911); SCHOENBERG, Arnold. Structural functions of harmony. (Leonard Stein, ed.) Nova York: W.W. Norton \& Company, 1969; SCHOENBERG, Arnold. Coherence, counterpoint, instrumentation in form. (Severine Neff, ed.; Severine Neff \& Charlotte Cross, trad.). Lincoln: University of Nebraska Press, 1994.

2 Entretanto, isso não impede que, sob um ponto de vista bastante flexivel e, em certos casos, com uma grande dose de abstração e/ou liberdade, analistas consigam interpretar certos temas schoenberguianos atonais como que construidos numa das formas-padrão aqui consideradas. Ver, por exemplo, a análise feita por LEHRDAL (2001, p. 353-61) da primeira das Três Peças para Piano, op.11, de Schoenberg, cujo principal tema demonstra ser estruturado como periodo. A bem da verdade, o op.11 é a obra inaugural da fase atonal schoenberguiana, que passa a tomar ainda no mesmo ano de sua composição (1909) uma nova direção, com a busca deliberada pela construção atemática, como bem exemplificam os op. 16 (Cinco Peças para Orquestra), 17 (o monodrama Erwartung) e 19 (Seis Pequenas Peças para Piano). Tal importante caracteristica (i.e., o atematismo), segundo CRAWFORD (1993, p.17-8), deve-se a razões não só musicais, como politicas, sociais e, principalmente às demandas geradas em outros campos artísticos, como a literatura, a pintura, a arquitetura, o cinema e o teatro, naquele fervilhante período conhecido como o Expressionismo alemão.

3 Para um detalhamento do periodo serial schoenberguiano e das particularidades de suas subfases ver PERLE (1962) e LEIBOWITZ (1997).

4 Baseada nas informações apresentadas em SCHOENBERG (1990, p. 20-81, capitulos V a VIII).

5 Segundo Schoenberg, todas as derivações possiveis (que ele mesmo classifica como motivos, Gestalten e figuras) de uma peça musical podem, de certa maneira, ser rastreadas de volta a um elemento inicial, o Grundgestalt, que traduzo como "idéia primordial". 0 conceito de Grundgestalt é definido pelo compositor em um texto que só recentemente foi publicado: SCHOENBERG (2006, p.27 e p. 129), baseado em manuscritos anteriores às anotações que deram origem a SCHOENBERG (1990). Neste último, escrito originalmente em inglês, não há qualquer menção a Grundgestalt. 0 que, no texto, mais se assemelha à sua definição é "basic motive", que julgo, contudo, ser um tanto ambíguo.

6 Presume-se que uma satisfatoriamente completa análise temática deva abordar dois aspectos interdependentes: o fraseológico (ou estrutural) e o motívico. A limitação de espaço, entretanto, obriga-me a restringir os comentátios do texto apenas ao foco principal deste estudo, que é a investigação sobre o emprego das formas-escolares definidas pela teoria na obra composicional schoenberguiana. A despeito disso, a análise motívica - imprescindivel para o pleno entendimento da estrutura dos temas -, não está por inteiro ausente neste exame, já que é apresentada suficientemente detalhada nos exemplos musicais. Pela mesma razão óbvia de espaço, não há aqui comentários sobre os contextos harmônicos dos temas, a não ser quando estes influenciam mais decisivamente, de alguma maneira, na construção arquitetônica.

7 A construção assimétrica desse tema também remete a Brahms, como mostra o interessante ensaio Brahms the progressive (SCHOENBERG, 1984, p. 398-441). Para assimetria e irregularidades em geral na disposição fraseológica ver também SCHOENBERG (1990, p.137-40).

8 PERLE $(1962$, p.123) considera "exagerada" a importância que Schoenberg atribui à "função formal de operações motivicas tradicionais" na organização estrutural de suas peças atonais e dodecafônicas. Segundo o autor, tais formas (entre as quais aquelas que tratamos neste artigo) resultam intrinsecamente das necessidades e particularidades da tonalidade e, portanto, seu emprego seria incoerente na música nova.

9 Numa perspectiva diversa de Perle (ver a nota anterior), ROSEN (1983, p.108), referindo-se ao emprego das formas cíclicas clássicas por Schoenberg em sua música dodecafônica (o que pode, certamente, ser também estendido ao nível microscópico da construção temática), afirma que para o compositor "as formas não se impõem à música, e sim, realizam-se mediante a música (...). Schoenberg (...) empregou essas formas como se tivessem propriedades expressivas inatas."

10 LEIBOWITZ (1997) analisa detalhadamente o Op.31, apresentando as diversas novas possibilidades ali criadas para o manejo da série.

11 Tradução do original, em inglês, developing variation. Trata-se, basicamente, do conjunto de técnicas e procedimentos que permitem variar elementos motívicos que, por sua vez, são também obtidos por variações, criando assim um processo que pode se estender indefinidamente. Embora a variação em desenvolvimento possa ser detectada em obras de compositores de periodos anteriores (principalmente Beethoven), foi a partir da análise de composições de Brahms que Schoenberg conseguiu elaborar tal princípio, assimilando-o em sua própria prática composicional. Para maiores informações a respeito, ver o ensaio Brahms, the progressive in SCHOENBERG (1984, p. 398-441) e o livro Brahms and the principle of developing variation (FRISCH, 1984).

12 Isto é, reduz gradualmente a idéia, eliminando o material mais importante, deixando apenas resíduos. Para mais informações sobre os processos de liquidação, ver SCHOENBERG (1990, p. 58-59). 
13 Uma sucinta análise harmônico-formal do tema e de suas variações pode ser encontrada em NELSON (1964, p.160-3).

14 A respeito da flexibilidade construtiva é também pertinente comentar sobre o conceito de "prosa musical" [musical prose], elaborado por Schoenberg a partir de análises da obra de Wagner e, principalmente, de Brahms. Schoenberg define a prosa musical como "uma apresentação de simples e diretas idéias, sem qualquer artesanato, sem meras repetições vazias e enfadonhas" (SCHOENBERG, 1984, p. 415). É interessante perceber que sua contrapartida, que poderia ser denominada "poesia musical" reflete uma construção mais quadrática e simétrica, justamente semelhante àquelas propostas pelas formas-padrão do periodo e da sentença. Ao flexibilizá-las, alternado a extensão dos "versos" / frases e ao fugir das "rimas" / correspondências esperadas, Brahms (e, como mostra este artigo, também Schoenberg) alcançam naturalmente a expressão prosaica, a partir do mesmo modelo construtivo.

Carlos de Lemos Almada é flautista, compositor, arranjador, professor e autor de livros sobre teoria musical e análise (Arranjo. Campinas: Editora da Unicamp, 2000; A estrutura do choro. Rio de Janeiro: Da Fonseca, 2006 e Harmonia funcional. Campinas: Editora da Unicamp, no prelo). Atualmente é doutorando em Música pela Universidade Federal do Estado do Rio de Janeiro, cuja pesquisa visa a análise da estrutura harmônica da Primeira Sinfonia de Câmara, op.9, de Arnold Schoenberg, dando continuidade a estudo realizado sobre a estrutura formal da mesma obra, durante o mestrado. 